\title{
Information Security Culture for Guiding Employee's Security Behaviour: A Pilot Study
}

\author{
Akhyari Nasir ${ }^{1}$, Ruzaini Abdullah Arshah ${ }^{2}$, Mohd Rashid Ab Hamid ${ }^{3}$ \\ ${ }^{1}$ Faculty of Computer, Media and Technology Management, TATI University College \\ Teluk Kalong, 24000 Kemaman, Terengganu, Malaysia \\ akhyari@tatiuc.edu.my \\ ${ }^{2}$ Faculty of Computer Systems \& Software Engineering \\ Universiti Malaysia Pahang, Lebuhraya Tun Razak, 26300 Kuantan, Pahang, Malaysia \\ ruzaini@ump.edu.my \\ Faculty of Industrial Management \\ ${ }^{3}$ Universiti Malaysia Pahang, Lebuhraya Tun Razak, 26300 Kuantan, Pahang, Malaysia \\ rashid@ump.edu.my
}

\begin{abstract}
Experts and scholars have suggested that cultivation of a positive Information Security Culture (ISC) could improve employee's security behaviour in organization. However, specific ISC model for employee's security behaviour is limited due to a lack of examination on the sole effect of ISC towards employee's security behavior. This paper discusses a pilot study of our research-in-progress that proposes a holistic ISC model to be used as guidance for employee's security behaviour in organization. ISC concept developed in the study is represented by seven comprehensive dimensions formulated based on widely accepted concepts of Organizational Culture and ISC. Theory of Planned Behaviour (TPB) was used to form the nomological core that link ISC with security behaviour in the research model. The model was tested in a Malaysian public university. This study employed Partial Least Square Structural Equation Modelling (PLS SEM) using Smart PLS 3 software to analyse and validate the model. The findings proved that the ISC model is significant in influencing security compliance behaviour. Hence, this study contributes to ISC literature in terms of development and empirical validation of a new ISC model based on seven comprehensive dimensions in relation with ISP compliance behaviour.
\end{abstract}

Key words : information security culture; information security policy compliance; security behaviour; model; PLS-SEM. 